Quan, B. T., C.-H. Chung, S.-T. Lin and C.-W. Shen (2009): Quantifying height growth and monthly growing degree days relationship of plantation Taiwan spruce. Forest Ecology and Management. 257: 2270-2276.

Ruotsalainen, S. and D. LindGREN (1998): Predicting genetic gain of backward and forward selection in forest tree breeding. Silvae Genetica 47: 42-50.

SEARLE, S. L. (1971): Topics in variance component estimation. Biometrics 27: 1-76.

Stoehr, M. U., K. Bird, G. Nigh, J. Woods and A. YANCHUK (2010): Realized Genetic Gains in Coastal Douglas-fir in British Columbia: Implications for growth and yield projections. Silvae Genetica 59: 223-233

Stoehr, M. U., N. K. Ukrainetz, L. K. HaYton and A. D. YANCHUK (2009): Current and future trends in juvenile woood density for coastal Douglas-fir. Canadian Journal of Forest Research 39: 1415-1419.

Su, L-H (2004): Estimating breeding values and genetic gain of Cunninghamia lanceolata (Lamb.) Hook. var. Konishii from a 27-year progeny test with messy data. Master Thesis (in Chinese with English summary),
Department of Forestry, College of Agriculture and Natural Resources, National Chung Hsing University, Taichung, Taiwan.

TsuKADA, M. (1967): Vegetation in subtropical Formosa during the Pleistocene glaciation and the Holocene. Palaeogeography, Palaeoclimatology, Palaeoecology 3: 49-64.

WU, H. X. and C. C. YING (2004): Geographic pattern of local optimality in natural populations of lodgepole pine. Forest Ecology and Managemnt 194: 177-198.

YANG, J. C. and J. D. ChUNG (1999): Preliminary study on hybridity among Cunninghamia lanceolata, Cunninghamia konishii, Cryptomeria japonica, and Taiwania cryptomerioides (in Chinese with English summary). Taiwan Journal of Forest Science 14: 437-446.

YANG, J. C., C. H. LeE and C. M. ChIU (2001): Genetic variation of wood density in Luanta fir tested in central Taiwan. Wood and Fiber Science 33: 486-491.

Zobel, B. J and J. P. VAN BuiJTEnen (1989): Wood variation: its causes and control. Springer-Verlag, New York, NY.

\title{
The effectiveness of phenotypic selection in natural populations: a case study from the Peruvian Amazon
}

\author{
By J. P. Cornelius ${ }^{1, *}{ }^{*}$, C. Sotelo Montes ${ }^{2)}$, L. J. Ugarte-Guerra ${ }^{3)}$ and J. C. Weber ${ }^{2)}$
}

(Received $3^{\text {rd }}$ September 2010)

\begin{abstract}
Phenotypic selection is commonly used in agroforestry, both in genetic improvement and as a component of "good practice" in seed collection. In the first case, the aim is to secure genetic gain. In the second case, selection is used to ensure that seed supplies meet given minimum quality standards, or that poor quality sources are avoided. Here we examine the effectiveness of phenotypic selection in natural forest stands of the Amazonian timber and multipurpose tree Calycophyllum spruceanum Benth.. We ask (a) whether mothertrees with high estimated annual height and diameter increments had faster growing progeny than mothertrees with low values; (b) whether forked mother-trees tended to have higher proportions of forked progeny than unforked trees; (c) whether spatially isolated moth-
\end{abstract}

\footnotetext{
1) Agroforestry and Novel Crops Unit, School of Marine and Tropical Biology, James Cook University, P.O. Box 6811, Cairns, QLD 4870, Australia. E-Mail: jonathan.cornelius@jcu.edu.au.

${ }^{2}$ ) World Agroforestry Centre (ICRAF), West and Central Africa Sahel Office, B.P. E5118, Bamako, Mali.

3) World Agroforestry Centre (ICRAF), CIP, Apartado Postal 1558, Lima 12, Peru.

*) Communicating author: JonATHAN P. CoRnelius. Phone +61-7-40421789. E-Mail: jonathan.cornelius@jcu.edu.au.
}

er-trees tend to produce slower growing progeny than mother-trees growing together with conspecifics. In each case, we found no evidence of differences between the respective groups. We offer explanations for these findings and discuss their implications for tree improvement and seed collection.

Key words: Calycophyllum spruceanum, progeny-test, tree domestication, tree improvement, seed collection, tropical rainforest.

\section{Introduction}

Phenotypic selection is used commonly in agroforestry, both in genetic improvement programmes (e.g. MESÉN et al., 1994) and as a component of "good practice" in seed collection (e.g. MULAWARMAN et al., 2003). In the first case, the aim is to secure genetic gain. In the second case, selection is used to ensure that seed supplies meet given minimum quality standards, or that poor quality sources are avoided.

Phenotypic selection involves a cost. Therefore, its effectiveness is of interest. CoRnELIUS (1994a) established that plus-tree selection for yield can be effective. However, there were indications that selection is less effective in wild stands than in plantations. There are 
two principal reasons why this is likely to be the case. First, environmental factors in natural forests (pests and diseases, competition, soil physical and chemical characteristics, etc.) are generally less controlled and therefore more variable than in plantations. Second, trees in natural populations may vary in age. Because of both factors, phenotype in natural stands will tend be less indicative of genotype, i.e. heritability will tend to be lower, which reduces the effectiveness of selection.

Here we examine the effectiveness of phenotypic selection in natural forest stands of the Amazonian timber and multipurpose tree Calcycophyllum spruceanum Benth. We ask three specific questions. First, whether mother-trees with high estimated annual height and diameter increments had faster growing progeny than mother-trees with low values of the same variables. SOTELO et al. (2006) reported heritabilities of height and diameter for C. spruceanum of between 0.24 and 0.3 , i.e. substantially $>0$ and towards the high end of ranges typical in forest trees (CoRNELIUS, 1994b). However, these estimates were based on progeny-tests of the populations studied here; for the reasons explained above, we would not necessarily or probably expect them to apply here.

Second, whether forked mother-trees tended to have higher proportions of forked progeny than unforked mother-trees. Third, as seed collection guidelines frequently indicate that seed trees should not be isolated from conspecifics, we examine whether isolated C. spruceanum trees produce slower growing offspring than those growing together with conspecifics. Seed collection guidelines recommend avoidance of isolated individuals because, in self-compatible species or individuals, isolation could lead to higher rates of selfing (MURAWSKI and HAMRICK, 1991) and, possibly, inbreeding depression in the progeny (e.g. GIGORD et al., 1998). For example, NAVARRo and HERNÁNDEZ (2004) found that progeny of isolated mahogany (Swietenia macrophylla King) trees tended to be slower growing than progeny of individuals growing in continuous forest tracts. They attributed this to selfing, which, although unusual in S. macrophylla, is known to occur (LEMES et al., 2007).

\section{Materials and Methods}

Study species

C. spruceanum is a long-lived pioneer species found in open or disturbed situations in riparian, floodplain, and other types of forest throughout the Amazon basin (REYNel et al., 2003; Sotelo Montes et al., 2003). The breeding system of $C$. spruceanum is unknown, although at least one congener ( $C$. candidissimum) has been reported to be self-compatible (BAWA, 1974). The strong, dense timber of C. spruceanum (Sotelo Montes et al., 2006) is one of the most traded on the Peruvian domestic market (IтTо, 2005). The species also has multiple on-farm (non-traded) uses, including medicinal applications (REYNEL et al., 2003).

\section{Mother-trees and progeny test}

In 1995, World Agroforestry Centre (ICRAF) staff surveyed preferences of small farmers in the Peruvian
Amazon. They found that farmers considered C. spruceanum to be one of the species of highest priority for participatory domestication (SOTELO MONTES and WEBER, 1997). In response, ICRAF began a participatory domestication programme. Open-pollinated seeds were collected in September-October 1998 from 66 farmerselected mother-trees growing on farms in seven locations (provenances) in the lower, middle and upper parts of the watershed Aguaytía watershed, Ucayali Region (see WEBER et al. (2009) for provenance locations), and the same number of randomly selected trees per provenance. As farmers' reasons for selecting individual trees varied considerably, there was no overall intensive selection for any one trait. Phenotypic data, including total height, trunk diameter at $1.3 \mathrm{~m}$, and forking incidence, were collected for random and selected mother-trees. In addition, the farmers estimated the age of each tree. These estimates are most likely to be reliable for trees that regenerated naturally in swidden fields, as farmers often remember when such fields were last cultivated. The following environmental variables were also collected for each tree: topographic location (hilltop, slope, flatland, or potentially floodable depression on flatland), soil texture (sandy, clayey, silty, other), spatial characteristics (isolated tree, in copse of $<10$ mature conspecifics, in woodland of $<50$ mature conspecifics, in extensive woodland of $>100$ mature conspecifics), flooding status (i.e. whether regularly flooded), land-use (home garden, swidden field, secondary forest $(<10$ years), secondary forest ( $>10$ years), pastureland, riverside, and palm association).

A multiple site provenance-progeny test was established, with replications located in the lower, middle and upper parts of the Aguaytía watershed (see WEBER et al., 2009 , for full details). Seedlings were grown in the nursery in a replicated experimental design similar to that used in the field (described below). After 15 months, they were transplanted into the provenance/progeny test. The test was established in the lower, middle and upper parts of the Aguaytía watershed. The experimental design was a randomized complete block with split plots. Ten replications were established on different farms: three each in the lower and middle planting zones, and four in the upper zone. In each replication, the selected and random groups were randomly assigned to two main plots, and the families in each group were randomly assigned to 66 sub plots, each containing two trees. Spacing was 2.5 by $2.5 \mathrm{~m}$ within and between rows. Two rows of border trees surrounded each main plot. Dead trees were replaced during the first dry season: replants were not included in the analyses of tree growth and stem bifurcations. Management practices are detailed in WEBER et al., 2009.

At 38 months after planting, tree height was measured to the nearest $\mathrm{cm}$ using a meter stick or telescopic measuring pole. Stem diameter at $10 \mathrm{~cm}$ above ground was measured to the nearest $0.1 \mathrm{~cm}$ using callipers or diameter tape. The full statistical analysis is described elsewhere (WEBER et al., 2009). The data for our analysis were the overall family means across the experiment for height, diameter, and proportion of trees with forks, all at 38 months. 


\section{Trait comparisons: growth rate}

When the selections were made, the farmers generally did not emphasize tree size or growth increment. Indeed, in several populations, the mean heights or diameters of selected trees were lower than those of random trees. Consistent with this, progeny-test data suggest that this selection has not had any genetic consequences (i.e. neither in reducing genetic variances nor in changing mean values for growth variables) (WEBER et al., 2009). Here we look not at the genetic effect of the actual selection, but at the potential effect of alternative selection strategies aimed at increasing growth rate.

Plus-tree selection practitioners use various approaches to attempt to minimize the effects of age and environmental differences (LEDIG, 1974; MoRGEnstern et al., 1975). In order to reflect such practice, in each population we identified mother-trees with the same values of the environmental variables (for land-use type, old and young secondary forests were considered to represent the same conditions, on the assumption that in both cases the $C$. spruceanum trees were established during the early successional stage). We then estimated annual height increment as total tree height $\div$ estimated age. The trees were then sorted into pairs. When more than two trees in a population had the same environmental conditions, the two trees which differed most in height increment were first paired, and then the same procedure was used with the remaining trees until $\leq 1$ tree remained unpaired. The tree with highest height increment of each pair was considered to have been notionally selected, independent of whether it was from the actual "random" group or the "selected" group. Pairs with a height increment difference of $<20 \%$ were eliminated, as we were interested only in testing effects of phenotypic selection of appreciable intensity. We then used a paired t-test to test the null hypothesis that the notional phenotypic selection for height growth rate was ineffective, comparing the progeny-test mean heights of progeny of notionally selected trees with that of notionally unselected trees. We followed the same procedure for diameter increment at $1.3 \mathrm{~m}$ (note that the pairs were not the same in each case, as the tallest tree did not always have the highest diameter). Trees were paired only within populations because temperature and rainfall differences between collection sites would have vitiated between-population pairing.

As possible errors in age estimation imply errors in growth increment estimation, we repeated the above pairing process using the actual height and diameter of the mother-trees, rather than the estimated increments. This approach has the drawback of confounding size differences due to age with size differences due to growth rate.

\section{Stem forking}

WEBER et al. (2009) reported that there was no overall difference in forking incidence between progeny of selected and random trees. However, as not all random trees were forked, this finding did not establish conclusively that selection against forking is ineffective. Here, using an unpaired t-test, we compare the overall progeny-test progeny mean forking incidence for all forked trees versus all unforked trees, regardless of whether the latter were random or selected trees. In addition, we carried out an analysis following the same within-population pairing procedure as for growth, on the assumption that environment could affect the tendency to fork and could therefore usefully be corrected for.

\section{Tree isolation}

We compared the height and diameter means of progeny of isolated mother-trees with those of mother-trees from groups of $\geq 50$ conspecifics. On the assumption that the environmental factors used for pairing in the case of growth variables would not affect selfing rate, no pairing was carried out for this case. Consequently, the null hypothesis was tested using an unpaired t-test.

\section{Results}

\section{Selection for growth rate}

We were able to identify 13 pairs for height and diameter increments, 14 pairs for height, and 13 for diameter. Although there were appreciable differences in phenotypic means of notionally selected and notionally unselected mother-trees, the means of progeny of the two groups were the same or similar, and not significantly different (Table 1).

Table 1. - Means of growth variables of notionally selected and unselected mother-trees of Calycophyllum spruceanum and their progeny ${ }^{\mathrm{a}}$.

\begin{tabular}{|c|c|c|c|c|c|}
\hline Variable & $\begin{array}{l}\text { Mean phenotypic } \\
\text { superiority } \\
\text { (ad) of notionally } \\
\text { selected mother- } \\
\text { trecs }\end{array}$ & $\begin{array}{l}\text { Mean "/o phenotypic } \\
\text { superiority (sd) of } \\
\text { notionally selected } \\
\text { mother-trees }\end{array}$ & $\begin{array}{l}\text { Girand progeny- } \\
\text { test mean (se) of } \\
\text { progeny of } \\
\text { notionally sclected } \\
\text { mother-1 rees }\end{array}$ & $\begin{array}{l}\text { Grand progeny-test } \\
\text { mean (se) of progeny } \\
\text { of notionally } \\
\text { unselected mother- } \\
\text { trees }\end{array}$ & $\begin{array}{c}\text { Significance of } \\
\text { difference between } \\
\text { plogeny of notionally } \\
\text { selected and unselected } \\
\text { trees }\end{array}$ \\
\hline Height increment (m) & $1.13(1.00)$ & $134.3 \%(164.9 \%)$ & $6.3(0.21)(9.0 \mathrm{yr})$ & $6.0(0.13)(13.5 \mathrm{yr})$ & $\mathrm{t}-1.0(\mathrm{P}-0.17, \mathrm{DF}-12)$ \\
\hline $\begin{array}{l}\text { Djameter increment } \\
(\mathrm{cm})\end{array}$ & $1.5(1.2)$ & $84.3 \%(96.8 \%)$ & $9.0(0.3)(8.5 \mathrm{yr})$ & $9.0(0.2)(12.8 y)$ & test unncecssary \\
\hline Height (m) & $6.0(4.6)$ & $76.8 \%(74.6 \%)$ & $6.2(0.18)$ & $6.1(0.17)$ & $\mathrm{t}-0.42(\mathrm{P}-0.34, \mathrm{D \Gamma}-1.3)$ \\
\hline Diameter & $9.9(4.8)$ & $56.5 \%(38.5 \%)$ & $8.8(0.3)$ & $8.8(0.3)$ & test unnecessary \\
\hline
\end{tabular}

${ }^{\mathrm{a}} \mathrm{sd}=$ standard deviation, se=standard error, $\mathrm{t}=\mathrm{t}$-ratio for difference between means of progeny of notionally selected and notionally unselected mother-trees, $\mathrm{P}=$ one-tailed probability of the value of $\mathrm{t}$ under the null hypothesis, $\mathrm{DF}=$ degrees of freedom; ${ }^{b}$ i.e. $\left[\Sigma\left[x_{s}-x_{u}\right]\right] / \mathrm{n}$, where, in a given pair, $\mathrm{x}_{\mathrm{s}}$ is phenotypic value of the notionally selected tree and $\mathrm{x}_{\mathrm{u}}$ is phenotypic value of the notionally non-selected tree, $\mathrm{n}$ is number of pairs. 


\section{Forking}

The mean forking incidence of progeny of all unforked trees was 0.18 (s.e. $=0.01, \mathrm{~N}=95$ ), whereas the mean forking incidence of progeny of all forked trees was 0.20 (s.e. $=0.04, \mathrm{~N}=23) \quad(\mathrm{t}=0.62, \mathrm{DF} 26.6, \mathrm{P}=0.27$ (t-test adjusted for inequality of variance)).

Six forked/unforked pairs with the same values of the environmental variables were identified across the various populations. In the case of these paired trees, the mean forking incidence of progeny of forked trees was 0.20 (s.e. $=0.06$ ), whilst the mean forking incidence of progeny of unforked trees was 0.22 (s.e. $=0.06)$. The difference was non-significant $(t=0.232, \mathrm{DF}=5, \mathrm{P}=0.83$ ).

\section{Tree isolation}

There were 24 isolated trees and 30 trees in groups with $>50$ conspecifics. The mean heights and standard errors of progeny of isolated and non-isolated trees were the same $(6.2 \mathrm{~m}$, s.e. $=0.1)$. Diameter means were also the same $(9.0 \mathrm{~cm}$, s.e. $=0.17,0.16$ respectively for isolated and non-isolated trees).

\section{Discussion}

As phenotypic selection for growth rate in plantations is generally effective (CORNELIUS, 1994), selection in natural forest might be expected to be successful in two situations: when the phenotypic variation caused by environmental or age effects is of similar magnitude to that in plantations, or when such variation can be taken into account by selecting within relatively environmentally homogenous conditions. Our results suggest that the approaches to reducing age-related and environmental variation that we have modelled here are unlikely to be successful. There is no obvious solution to this problem. Conceivably, relative age of candidate-trees could be assessed by evaluation of growth rings, but the problem of accounting for the multiple sources of spatial and temporal environmental variation would remain. It is almost inevitable that trees of different ages will have experienced different environmental conditions at comparable ages (e.g. of rainfall, dry season length, browsing incidents) even if there are no spatially correlated environmental differences between them, and it is difficult to see how such differences can even be known, let alone adjusted for. Even in even-aged stands on relatively uniform sites, within- and between-species competition and other biotic interactions are likely to lead to environmentally caused variation of much greater magnitude than seen in evenly-spaced, managed plantations.

Our results suggest that there is little to gain from avoiding forked trees in seed collection of natural stands of $C$. spruceanum. The simplest explanation for this finding would be that forking is not due to genetic factors, but directly to environmental effects such as biotic or abiotic mechanical damage. This explanation ignores the possibility that response to mechanical damage could have a genetic component. If this is the case, then whereas forked trees are those that have been mechanically damaged but have not responded by regaining api- cal control, unforked trees have either not been subjected to the sort of factors that have caused the forked trees to fork, or they are trees that have responded to such factors by regaining or never losing apical control. This interpretation does not affect the conclusion that there is little point in avoiding forked trees. But it does also suggest that, in other situations, it may be possible to select against forking, i.e. by applying artificial mechanical damage to each tree. Such a strategy has been suggested in screening for tolerance to Hypsipyla shoot-borer damage in Meliaceae (NEWTON et al., 1996; CoRnelius, 2009). However, such techniques are only feasible with relatively small trees in an experimental setting and are not directly relevant to the present context.

Finally, our results indicate that progeny of isolated trees are not slower growing than progeny of trees growing close to conspecifics. This suggests that either C. spruceanum is self-incompatible, or, if self-compatible, that the distance between trees in C. spruceanum is not correlated with selfing rates, or that selfing does not lead to inbreeding depression.

Our results can to some extent be extrapolated to other species, particularly in the case of growth and forking. In the former, it seems likely that the environmental and age factors that we have invoked to explain the ineffectiveness of selection are as likely to be as present in other species as in C. spruceanum. In the case of forking, our results are most applicable to other species with similar architectural patterns. They have little relevance to species that usually or commonly produce multiple leaders or to situations where all trees have been exposed to mechanical damage and where therefore all unforked trees are trees that have recovered or maintained apical control, as opposed to being "escapees". Shoot-borer attack in Meliaceae, which often approximates $100 \%$ in young plantations, is one such case. Finally, the effect of mother-tree isolation on progeny performance depends on interactions between spatial distribution, pollinator type, breeding systems, and response to inbreeding. Our results on this aspect therefore have little generality beyond the specific case presented (i.e. C. spruceanum). They do, however, suggest that isolated trees of this species should not automatically be discounted from inclusion in breeding programmes and as seed sources.

Our findings have implications for the use of phenotypic selection in agroforestry. First, seed collectors and tree improvers should in general not stress tree size or growth rate when selecting in structurally complex natural tropical forest. In both cases, time and funds would be better expended in selecting more trees (for a wider genetic base to facilitate genotypic selection via progeny testing) or, possibly, in looking for trees superior in other traits with higher degrees of genetic control (e.g. wood density) (Sotelo Montes et al., 2006). Second, both seed collectors and tree improvers should bear in mind that a forked tree may simply be exhibiting the same response to mechanical damage or some other factor that unforked trees would be exhibiting had they been so damaged. We would not argue, on this justification, that the absence of forking should no longer be used as a 
selection criterion. However, if a given tree were of unusually good phenotype in other respects, then we would recommend collecting from it if comparable unforked trees were not available. Similarly, in the case of C. spruceanum, spatially isolated trees of unusually good phenotype should be included in collections - for both seed supply and in tree improvement. In both cases (forking and isolation) we would argue that avoiding otherwise highly superior trees that are forked or isolated is more likely to result in omission of a superior genotype than in "congenitally forked" offspring or offspring with inbreeding depression. However, in both these cases, prudence should dictate that our findings should only modify current practice when comparable unforked or non-isolated trees are not available. Even in the case of selection for growth, our results need to be applied judiciously and should not be used to legitimize unscrupulous or poor seed collection practice, e.g. from obviously stunted or deformed trees with heavy seed production.

\section{Acknowledgments}

The logistical support of INIA (National Institute for Agricultural Research, Peru) and the financial support provided by the European Union and the World Bank are gratefully acknowledged.

\section{References}

BAwA, K. S. (1974): Breeding systems of tree species of a lowland tropical community. Evolution 28: 85-92.

Cornelius, J. P. (1994a): The effectiveness of plus-tree selection for yield. For Ecol Manage 67: 22-34.

CoRnelius, J. P. (1994b): Heritabilities and additive genetic coefficients of variation in forest trees. Canadian Journal of Forest Research 24: 372-379.

Cornelius, J. P. (2009): The utility of the predictive decapitation test as a tool for early genetic selection for Hypsipyla tolerance in big-leaf mahogany (Swietenia macrophylla King). For Ecol Manage 257: 1815-1821.

Gigord, L., C. Lavigne and J. A. ShyKoff (1998): Partial self-incompatibility and inbreeding depression in a native tree species of La Réunion (Indian Ocean):. Oecologia 117: 342-352.

ITTO (International Tropical Timber Organization (2005): Status of tropical forest management 2005. Country report: Peru. www.itto.int/en/sfm_detail?id=1801. Accessed 29 June 2009.

LEDIG, F. T. (1974): An analysis of methods for the selection of trees from wild stands. Forest Sci 20: 2-16.

Lemes, M. R., D. Grattapaglia, J. Grogan, J. Proctor and R. GRIBEL (2007): Flexible mating system in a logged population of Swietenia macrophylla King (Meli- aceae): implications for the management of a threatened neotropical tree species. Plant Ecol 192: 169-179.

Mesén, J. F., D. H. Boshier and J. P. CoRnelius (1994): Genetic improvement of trees in Central America, with particular reference to Costa Rica, pp 249-255. In: Tropical Trees: the potential for domestication and the rebuilding of forest resources, edited by R. R. B. LEAKEY and A. C. NEWTON, HMSO, London.

Morgenstern, E. K., M. J. Holst, A. H. Teich and C. W. E. Yeatman (1975): Plus-tree selection: review and outlook. Canadian Forest Service Publication 1347. Ottawa, Ontario.

Mulawarman, J. R. Roshetko, S. M. SAsongko and D. IRIANTO (2003): Tree seed management - seed sources, seed collection and seed handling: a field manual for field workers and farmers. International Centre for Research in Agroforestry and Winrock International, Bogor, Indonesia.

MURAWSKI, D. A. and J. L. HAMRICK (1991): The effect of density of flowering individuals on the mating systems of nine tropical tree species. Heredity 67: 167-174.

Murawski, D. A. and J. L. HAMrICK (1992): The mating system of Cavanillesia platanifolia under extremes of flowering tree density: a test of predictions. Biotropica 24: $99-101$.

NAvARro, C. M. and G. Hernández (2004): Progeny test analysis and population differentiation of Mesoamerican mahogany (Swietenia macrophylla). Agronomía Costarricense 28: 37-51.

Newton, A. C., J. P. Cornelius, F. Mesén and R. R. B. LEAKEY (1995): Genetic variation in apical dominance of Cedrela odorata seedlings in response to decapitation. Silvae Genet 44: 2-3.

Reynel, C., T. D. Pennington, R. T. Pennington, C. Flores and A. DAZA (2003): Arboles útiles de la Amazonia peruana y sus usos, Universidad Nacional Agraria La Molina, Lima.

Sotelo Montes, C. and J. C. Weber (1997): Priorización de especies arbóreas para sistemas agroforestales en la selva baja del Perú. Agroforestería en las Américas 4: 12-17.

Sotelo Montes, C., H. VidaurRe and J. C. Weber (2003): Variation in stem-growth and branch-wood traits among provenances of Calycophyllum spruceanum Benth. from the Peruvian Amazon. New Forest 26: $1-16$.

Sotelo Montes, C., R. Hernández, J. Beaulieu and J. C. WEBER (2006): Genetic variation and correlations between growth and wood density of Calycophyllum spruceanum Benth. at an early age in the Peruvian Amazon. Silvae Genet 55: 217-228.

Weber, J. C., C. Sotelo Montes, J. Ugarte and A. J. Simons (2009): Phenotypic selection of Calycophyllum spruceanum on farms in the Peruvian Amazon: evaluating a low-intensity selection strategy. Silvae Genet 58: 172-179. 